\title{
"Uma pequena aldeia": síntese da presença do mito de Penélope na poesia de Cecília Meireles
}

\author{
Denise de Carvalho Dumith*
}

\begin{abstract}
Resumo: Este trabalho busca apontar a presença do mito de Penélope na poesia de Cecília Meireles e demonstrar sua importância, analisando-o comparativamente com o mito homônimo na Odisséia, de Homero. Outra meta é desnudar a reatualização mítica da autora na criação de seu universo textual encantatório. Realiza-se então um estudo mitocrítico, no qual Penélope em Cecília Meireles é enfocada a partir de seus principais mitemas, o da tecelã e o da mulher que espera o amado. Porém, conforme uma característica da criação ceciliana, ao mesmo tempo em que retoma o mito homérico na versão 'original', acrescenta-lhe uma nova face: a mística. As reflexões de Gilbert Durand sobre o estudo do mito que resultam na mitodologia e as considerações de Ana Maria Lisboa de Mello sobre a obra da poeta fornecem os principais aportes teóricos.
\end{abstract}

Palavras chave: mito de Penélope; Cecília Meireles; poesia.

\begin{abstract}
This essay analyzes the myth of Penelope in Cecilia Meireles's poetry and establishes a comparative investigation with the presentation of the same myth in Homer's Odyssey. Another aim is to show how the author recreates the Penelope myth in her enchanting textual universe. A critical myth research is thus developed, in which Cecilia Meireles's Penelope is analyzed according to its main mythems, namely the woman weaver and the woman who expects her love. Meireles not only recovers the Homeric myth in its "original" version, but also adds a new mystical face to it. The reflections by Gilbert Durand on the study of myth which result in mythodology and the considerations by Ana Maria Lisboa de Mello on Cecilia Meireles's work are the main theoretical background for this analysis.
\end{abstract}

Keywords: Penelope's myth; Cecilia Meireles; poetry.

Ao comentar a reatualização mítica, Jacqueline Fabre-Serris afirma: "mais que os historiadores e os filósofos, são, a nosso ver, os poetas que conferiram um sentido moderno aos velhos relatos da mitologia, colocando-os em relação com as novas exigências morais, intelectuais e políticas de uma sociedade em mutação" (1998, p. 23). Tais palavras vêm ao encontro de considerações anteriores de Cecília Meireles, ao refletir que "a literatura nos mostra o homem com uma veracidade que as ciências talvez não têm. Ela é o documento espontâneo da vida em trânsito. É o depoimento vivo, natural, autêntico". E acrescenta: "quando um poeta canta é que nele se operou todo um processo de síntese: sua sensibilidade,

\footnotetext{
* Denise de Carvalho Dumith é doutoranda do Programa de Pós-Graduação em Letras da UFRGS e pesquisadora do mito de Penélope, tema sobre o qual desenvolveu monografia e dissertação; seu último trabalho consiste na elaboração do verbete "Migrações do mito de Penélope nas Américas" in Dicionário de figuras e mitos literários das Américas, organizado por Zilá Bernd, publicado em novembro de 2007.
} 
sua personalidade recolheu os elementos esparsos do momento, da raça da terra, dos contatos sociais e espirituais" (1929, p. 23). Devido a essa capacidade de recepção das mensagens do mundo, verifica-se no decorrer da obra poética de Cecília Meireles uma constante presença do mito de Penélope, fulcro desta análise.

Porém, Gilbert Durand postula que não adianta querer explicar um mito, reduzi-lo à pura linguagem. No entanto, é possível classificar suas estruturas, seus moldes, pois se trata de um "enxame semântico" (2002, p. 373). A fim de fornecer suporte teórico à investigação do mito, Durand instaura a mitodologia, dicotomizada em mitocrítica e mitanálise. Esta última abrange, em resumo, o estudo do contexto onde se insere o mito, cuja amplitude impede a execução por meio da brevidade ensaística. Já a mitocrítica consiste no estudo da base literária dos mitos, especializada na análise de textos e no estudo dos mitos literários, a fim de assegurar-lhe o rigor científico.

Durand afirma ainda que a análise crítica dos mitos literários ultrapassa as barreiras impostas pela história porque "a perenidade dos mitos não se prende a uma situação de começo, mas à capacidade de irrigar não importa qual momento histórico, alargando um espaço e um tempo míticos, aistóricos e meta-históricos" (MONNEYRON; THOMAS, 2002, P. 81). Assim sendo, o mito representa um pouco a memória da sociedade. Na qualidade de exemplo dessa memória, destaca-se a figura penelopiana, que povoa o imaginário ocidental há, pelo menos, nove séculos antes de Cristo, mantendo-se, não obstante a passagem do tempo, sempre atual.

Tanto permanece, que, no conjunto da poesia de Cecília Meireles, a reatualização mítica de Penélope é tema recorrente, embora o único poema em que há referência a esse antropônimo seja "Uma pequena aldeia". A leitura do eu lírico ceciliano sobre tal mito distribui-se em trinta versos brancos agrupados em seis estrofes heterométricas e heterorrítmicas. Essa apresentação, pelo fato de não se prender à fixidez formal, sugere a idéia de impermanência, uma constante na poética da autora, para quem "a vida é uma perpétua instabilidade e que a sua forma de definição suprema é a constância de um movimento de sempre renascentes ritmos" (1929, p. 10). Confira-se:

\footnotetext{
1 No canto do galo há uma pequena aldeia

2 de mulheres risonhas e pobres

3 que trabalham em casa de pedra

4 com belos braços brancos

5 e olhos cor de lágrima.

6 São umas corajosas mulheres

7 que tecem em teares antigos,

8 são umas Penélopes obscuras

9 em suas casas de pedra
} 
10 com fogões de pedra

11 nestes tempos de pedra.

12 Elas, porém, cantam com frescura,

13 a leveza, a graça, a alegria generosa

14 da água das cascatas,

15 que corre de dentro do mundo

16 pelo mundo

17 para fora do mundo.

18 No canto do galo há, de repente,

19 essa pequena aldeia,

20 com essas belas mulheres,

21 essas boas deusas escondidas,

22 essas criaturas lendárias

23 que trabalham e cantam

24 e morrem.

$25 \mathrm{O}$ amor é uma roseira à sua porta,

26 o sonho é um barco no mar

27 a vida é uma brasa na lareira

28 um pano que nasce, fio a fio.

29 A morte é um dia santo

30 para sempre no céu. (MEIRELES, 2001, p. 1893)

No poema acima, o sujeito lírico manifesta-se em terceira pessoa, o que lhe proporciona o distanciamento necessário para dirigir seu olhar contemplativo, atento e terno a uma cena bucólica. Sob uma leitura parafrásica, constata-se que as quatro primeiras estrofes descrevem o dia-a-dia das mulheres, habitantes fixas de 'uma pequena aldeia', enfatizando as ações de trabalhar, tecer e cantar, executadas por elas, enquanto o canto do galo, envolve o lugarejo em todos os seus quadrantes. Sucede-se então, no quinto bloco, um apanhado sucinto do que significa para essas mulheres o amor e o sonho, os quais, como a vida, em que pese a fugacidade, precisam ser paciente e constantemente tecidos. A sexta, estrofe final, constitui-se por um dístico onde a poeta define a morte como sendo um feriado, ou pausa perene nas lides diárias, tempo eterno para meditação.

Previamente a qualquer análise mitocrítica, contudo, é mister lembrar que Durand define a unidade de base a partir da qual ele trabalha como sendo o mitema, o menor denominador comum de sentido simbólico (1996, p. 160). Durand toma emprestado o termo cunhado por Lévi-Strauss, ao pontuar que "o mito se define pelo conjunto de suas variantes, sem descartar, nem desvalorizar nenhuma", porquanto "a colocação em evidência dos mitemas permite revelar suas oposições fundamentais" (apud MONNEYRON; THOMAS, 2002, p. 47). No empreendimento da mitocrítica do mito de Penélope, é essencial fornecer, em primeiro lugar, a descrição de seus mitemas composicionais, observando um dos princípios do mito, segundo o qual, ele se define pela soma de suas versões. Não se trata de 
tentar apontar uma inacessível versão hipoteticamente definitiva, mas, para dar-lhe forma, deve-se procurar suas realizações mais antigas. Tal pensamento exclui, contudo, a hierarquia que visa a determinar apenas um exemplar mítico original e o único autêntico.

A elaboração literária debruça-se justamente sobre a escolha desses mitemas, sobre sua tradução, sua modificação em relação às colorações específicas da obra. Esses tons marcam o imaginário pessoal de cada autor. O imaginário de Cecília Meireles, segundo Ana Maria Lisboa de Mello, "assenta-se, sobretudo, na contemplação e inventário das formas de vida e modos de existir" (2002, p. 22), demonstrando que as manifestações da natureza, a atividade e a convivência humanas são observadas sob olhos atentos e registradas como poesia. Mello acrescenta que, "no simples, a poeta intui o Eterno" (p. 25), apreciação exemplificada pelo poema, pois o sujeito poético de "Uma pequena aldeia" detém-se na contemplação de coisas simples, nas quais capta a poesia escondida no cotidiano.

Nele, o mito de Penélope é reforçado, de modo implícito, através do mitema da tecelã, além de ser invocado de maneira explícita através do nome próprio. Ora, na Odisséia, a personagem Penélope, atormentada pelo assédio de 108 (número cabalístico) pretendentes ao trono do marido ausente, os quais dilapidam o patrimônio familiar em intermináveis banquetes, vale-se de um estratagema: comunica a todos que só se casará novamente quando terminar a confecção da mortalha do sogro Laertes. Porém, tece de dia e destece de noite, postergando, assim, por três anos, as bodas indesejadas, tempo que possibilita o retorno de Odisseu.

Observando-se como parâmetro o hipotexto, verifica-se uma clara subversão ao mito penelopiano, quando se constata não existir qualquer destaque a alguém em especial. Não se trata de um lugar onde haja uma mulher proeminente, membro de destacada família, e das demais, na condição de súditas. Por isso são obscuras, Penélopes anônimas; não é enfocada no poema a rainha de Ítaca, com o enaltecimento da obra-estratagema. O que o eu poético ressalta é a harmonia grupal, em razão da característica heraclitiana de Cecília Meireles, para quem não devem ser reproduzidos os exemplos, "porque o processo da vida não permite repetições" (1929, p. 11).

Por outro lado, na fábula de Homero, a jovem e bela Penélope, é separada do marido poucos meses após o casamento, devido à guerra de Tróia. Porém, durante vinte longos anos, espera saudosa, fiel e amorosamente. Essa ação configura-a como o paradigma da esposa exemplar no ocidente, constituindo-se em outro dos seus mitemas. No poema, não há qualquer referência aos homens da aldeia. Entretanto, a presentificação da espera a esses 
homens ausentes é feita através do sonho das belas mulheres, que remete a um barco no mar (v. 26), e reiterada pelos "olhos cor de lágrima” (v. 5).

Caso não bastasse a presença latente dessa ausência, por si só, a citação do antropônimo resgataria a condição da espera, de acordo com a afirmação de Ernst Cassirer, a exemplo dos estóicos e neoplatônicos do período helenístico: "a idéia de que o nome e a essência se correspondem em uma relação intimamente necessária, de que o nome não só designa, mas também é esse mesmo ser, [...] contém em si a força do ser" (2000, p. 17). Cecília Meireles vale-se intencionalmente do recurso econômico de invocar o nome, "vencendo todas as distâncias" (1929, p. 26), como estratégia de concisão que a poesia requer.

Essa espera apenas sugerida, diferente, portanto, do hipotexto, em que se apresenta fremente, perpassando-o na totalidade e constituindo o seu Leitmotiv, soma-se à inversão da tecedura como valor individual, aristocrático, para inaugurar uma face nova no mito de Penélope. O acréscimo de um mitema, além de não contrariar, reforça a natureza do mito, que concentra em si "o maior número possível de significações" (DURAND, 2002, p. 372), à espera, portanto, que os poetas lhe acrescentem significados.

O modus operandi de tal acréscimo faz-se pela sucessão de imagens singelas, plenas de significado simbólico, onde impera a ternura por parte do sujeito lírico. Essas imagens fornecem sentido ao texto, conforme reconhece Ana Mello: "no poema, as imagens repercutem umas nas outras, formando cadeias cujos elos produzem o tecido semântico" (2002, p. 22). Destarte, a recriação lírica da realidade de eterna mudança, mas plena de retomadas monótonas e árduas, reforça-se no poema pela repetição da expressão "de pedra" (v.3, 9, 10,11) e do vocábulo "mundo" (v. 15, 16, 17) transcendendo a sensibilidade física e aproximando-o da meditação.

A esse respeito, Mihae Son considera que a poesia moderna parece se mover mais do que nunca em direção a uma espécie de meditação espiritual, que, diferentemente daquelas que a precederam, ela coloca em primeiro plano, com a tendência imperceptível de se aproximar de um Absoluto (p. 19). A atitude positiva dessas mulheres frente ao desafio da rotina e à espera que transcende o retorno, caso seja vivenciada com concentração e dedicação, remete à visão do zen-budismo sobre a existência.

Explica-se: um seguidor zen-budista, acaso inquirido acerca do significado da iluminação transcendental suprema, poderia tanto responder, em termos ocidentais, que a iluminação consiste em apenas aceitar a vida da maneira como ela é, quanto dizer: "O cipreste no jardim!" (GAARDER, 2000, p. 74). Por isso, no poema, o amor é aproximado metaforicamente à roseira, que encerra em si a dicotomia da felicidade simbolizada pela rosa, 
e do sofrimento, pelo espinho; a vida é comparada à brasa que se consome ao produzir calor, irradiando luz, além do pano que é tecido penelopicamente por cada fio concreto e abstrato na trama dos nós, as circunstâncias. Enquanto tecem seus panos literais e metafóricos, constroem o ideal ético da salvação coletiva.

Cecília Meireles ressemantiza, portanto, o mito de Penélope em "Uma pequena aldeia". No poema, verifica-se a cristalina mudança de um "eu" individual para a coletividade, condição ratificada através da grafia do vocábulo Penélope no plural. Outra modificação demonstrada concerne à espera, cuja importância vital no poema épico homérico é subvertida pela aceitação do destino tal como ele se revela no poema lírico ceciliano. Resultante dessas transgressões, uma terceira face se desvela: a mítica, em "completo abandono das suas inquietações individuais", próxima à definição que a autora confere a um 'espírito vitorioso', pronta a "receber com serenidade igual tanto as derrotas como os triunfos, aceitando da vida todas as aparências de tristeza ou sofrimento, e tendo o heroísmo de as edificar em alegria durável; vendo, dissipados os limites do espaço, todas as criações conjugadas numa permanente unidade" (1929, p. 115).

\section{Referências}

CASSIRER, Ernst. Linguagem e mito. 4.ed. São Paulo:Perspectiva, 2000.

DUMITH, Denise de Carvalho. O mito de Penélope: de Homero a Patrícia Bins. 2002. 76 p. Monografia (Especialização). Universidade Federal de Pelotas, Pelotas, 2002.

- Maríada - uma odisséia em Janela do Sonho, de Patrícia Bins. 2005. 122 p. Dissertação (Mestrado). Fundação Universidade do Rio Grande, Rio Grande, 2005.

DURAND, Gilbert. Introduction à la mythodologie. Paris: Albin Michel, 1996.

- Método arquetipológico: da mitocrítica à mitanálise. In: Campos do imaginário. Lisboa: Piaget, 1998. . As estruturas antropológicas do imaginário. 3.ed. são Paulo: Martins Fontes, 2002.

FABRE-SERRIS, Jacqueline. Mythologie et littérature à Rome: la réecriture des mythes aux Iers. siècles avant et après J.-C. lausanne: Payot, 1998.

GAARDER, Jostein et alii. O livro das religiões. São Paulo: Companhia das Letras, 2000.

HOMERO. Ilíada. Rio de Janeiro: Ediouro, 1996. 
. Odisséia. Rio de Janeiro: Ediouro, 2000.

MEIRELES, Cecília. O espírito vitorioso. Tese apresentada ao concurso da cadeira de Literatura da Escola Normal do Distrito Federal em XCMXXIX.

. Uma pequena aldeia. Dispersos (1918-1964). In: Poesia completa. Rio de Janeiro: Nova Fronteira, 2001.

MELLO, Ana Maria Lisboa de. Construções do imaginário na obra de Cecília Meireles. In: 2002. . (org.). Cecília Meireles e Murilo Mendes (1901-2001). Porto Alegre: Uniprom,

. Poesia e imaginário. Porto Alegre: EDIPUCRS, 2002.

; UTÉZA, Francis. Oriente e Ocidente na poesia de Cecília Meireles. Porto Alegre: Libretos, 2006.

MONNEYRON, Frédéric \& THOMAS, Joël. Mythes et littérature. Paris: [s.n], 2002 